Research Article

Journal of Extension Education

Vol. 32 No. 4, 2020

DOI:https://doi.org/10.26725/JEE.2020.4.32.6621-6625

\title{
Awareness about Muga Culture among the College Students in Jorhat District of Assam, India
}

\author{
K. Ghosh ${ }^{1}$ and M. Saikia ${ }^{2}$
}

\begin{abstract}
A study was undertaken to compare the awareness about muga culture among the college students in Jorhat district of Assam. Significant differences were found between the male and female students, and between rural and urban students. On the other hand, significant differences were found in the case of awareness on muga culture between Arts and Science stream students, and Arts \& Commerce stream students.
\end{abstract}

Keywords: Muga culture; Awareness; College students; Arts stream; Commerce stream; Science stream.

\section{INTRODUCTION}

Assam is the third leading state among all the silk producing states of India after Karnataka and Andhra Pradesh. Assam produced 5315.6 MT of raw silk during 2019-20, which accounted for $14.84 \%$ of the country's total raw silk production of 35818.6 MT (Anonymous, 2020). Silk production of Assam is gradually increasing but still there is a gap between what has been achieved and what could have been achieved. The muga silkworm culture and muga silk cloth is closely associated with the socio-economic and cultural life of Assamese people. Muga silkworm is endemic to northeastern region of India and muga silk is the first Gl product of Assam (Saikia et al., 2016). Production of muga raw silk (240.5 MT during 2019-20) is very less in comparison to other vanya silks of India (Anonymous, 2020) as because muga silkworm cultivation is mainly done by the traditional method and due to outdoor nature of rearing it has to face the problem of pest and diseases and abnormal environmental conditions. Non availability of good seeds, shortage of food plants, lack of awareness about new technologies, lack of knowledge about marketing and gradual declining of youth participation in this culture are also constraints which play role in low production of muga silk. Muga silkworm culture is confined to a limited number of traditional

1. Department of Education, Nakachari College, Nakachari - 785635, Jorhat - Assam, India.

2. Department of Sericulture, Faculty of Agriculture, Assam Agricultural University - 785013, Jorhat, Assam, India. Received : 15-05-2021; Accepted : 12-07-2021 
farmers of the region. Youths are not coming up to adopt muga culture as their livelihood; it is regarded as glamourless vocation of illiterate people. Rani and Rampal (2016) mentioned that youths are losing interest and confidence in agriculture and allied activities; hence they are not willingly involved in agricultural operations About $70 \%$ of India's population is below the age of 35 years, making it the youngest nation in the world and this predominance is expected to last until 2050 which can be utilized for taking Indian agriculture to new heights by channelising their creative energies through development of appropriate skills, knowledge and attitude (Gangwar and Kameswari, 2016). To conserve the muga silkworm, Antheraea assamensis Helfer and thereby providing employment to the youth, youth must have knowledge and information about muga culture whether they are educated or not.

Studies on participation of rural youth in sericulture (Viswanatha et al., 2014), adoption of scientific technology by sericulture farmers (Kushwaha and Singhvi, 2013; Sreenivasa, 2014), role of women in sericulture (Upadhyay and Barman, 2013; Goswami and Bhattacharya, 2013; Mech and Ahmed, 2012), comparative study on awareness about sericulture among secondary school students (Ghosh and Saikia, 2017) etc. have been carried out by several researchers but there is no detailed study on awareness on muga culture among college students. Therefore, it is essential to study the awareness on muga culture among the college students of Jorhat district in Assam.

\section{METHODOLOGY}

\section{Study area}

Jorhat district in Assam has a rich tradition of muga culture with a production of 5 MT muga raw silk during the year 201819. Change of natural environment and global warming, adoption of new technology, application of marketing strategy demand active participation of educated youth to revive the industry. Jorhat is the most literate district of Assam with 15 general colleges out of which eight are in rural areas and seven are in the urban areas. Present study is confined to the students of these colleges.

\section{Sampling and Experimental Procedure}

Descriptive survey method was used for the present study and 458 students were selected from 15 colleges in Jorhat district of Assam byadopting Stratified Random Sampling Technique. Muga Culture Awareness Scale (MCAS) was developed by the investigators to measure the level of awareness about muga culture among the college students. This scale consists of 30 multiple choice items, focusing on six different areas of muga culture such as basic idea about muga silkworm, rearing technique, host plants, disease and pest, mounting and reeling. The schedule consisting of 50 items was given to subject experts who edited the contents of the draft and it was further given to language experts to examine the language of each statement of the items. The verified draft was tried on 50 students to find out the level of item difficulty. The computed item variance showed that 30 items out of 50 ranged from 0.40 to 0.60 of variance. 
Awareness about Muga Culture among the College Students in Jorhat District of Assam, India

Therefore, 30 items were retained in the final draft of the scale. Finally, the Test-Retest method was applied to find out the reliability of the scale and computed value reached at 0.83; it indicated that the scale has reliability at satisfactory level. The investigator ensured the content validity of the scale by seeking the opinions of the experts. For analysis and computation of results, the investigators used ' $z$ ' test and arithmetic mean as the statistical technique.

\section{FINDINGS AND DISCUSSION}

The mean score of awareness on muga culture among arts, commerce and science stream students were 13.92, 10.21 and 17.37 respectively. Table 1 reveals that Science stream students have more awareness than Arts, Commerce stream students. On the other hand, female (17.77) and urban students (16.55) of Science stream students had higher awareness than male, female and rural students of Arts, Commerce stream students. The present study revealed that there is significant difference in awareness on muga culture between male and female college students (the ' $z$ ' ratio is 0.35748 ; significant at $\mathrm{p}<.05)$. It means both the sexes do not have equal awareness on muga culture. On the other hand, significant difference was found in awareness level between rural and urban college students (the ' $z$ ' ratio is 2.17383; significant at $p<.05)$. It revealed that settlement plays a vital role on awareness on muga culture. Significant difference was found in awareness about muga culture between Arts and Science stream students; and Arts and Commerce stream students respectively (the ' $Z$ ' ratio is 6.83636; significant at 0.01 level and the ' $Z$ ' ratio is 4.79296; significant at 0.01 level). It revealed that 'stream' of the students play a vital role in awareness on muga culture. But, significant difference was not found in the case of awareness about muga culture between male and female students of Arts stream students and students belonging to rural and urban settlement of arts stream. Significant difference was not found between male and female students of science stream students and students belonging to rural and urban settlements of commerce stream respectively. Hence it is concluded that male and female students of Arts and Science stream have equal awareness on muga culture.

Table 1.

Awareness on Muga culture among the College students

\begin{tabular}{|c|l|c|l|}
\hline Sl. No. & \multicolumn{1}{|c|}{ Differences Between } & \multirow{2}{*}{ Z - Score } & \multicolumn{1}{|c|}{ Level of Significance } \\
\hline \multirow{2}{*}{1} & Male (All) & \multirow{2}{*}{0.35748} & significant at $p<.05$ \\
\cline { 2 - 2 } & Female (All) & \multirow{2}{*}{2.17383} & significant at $p<.05$ \\
\hline \multirow{2}{*}{2} & Rural (All) & \multirow{2}{*}{6.83636} & significant at $p<.01$ \\
\cline { 2 - 2 } & Urban (All) & \multirow{2}{*}{4.79296} & significant at $p<.01$ \\
\hline \multirow{2}{*}{3} & Arts (All) & Science (All) & \\
\cline { 2 - 2 } 4 & Arts (All) & Commerce (All) & \\
\cline { 2 - 2 } & &
\end{tabular}


Journal of Extension Education

\begin{tabular}{|c|c|c|c|}
\hline SI. No. & Difference Between & Z - Score & Level of Significance \\
\hline \multirow{2}{*}{5} & Science (All) & \multirow{2}{*}{10.75993} & \multirow{2}{*}{ significant at $p<.01$} \\
\hline & Commerce (All) & & \\
\hline \multirow{2}{*}{6} & Male (Arts) & \multirow{2}{*}{1.25812} & \multirow{2}{*}{ NS } \\
\hline & Female (Arts) & & \\
\hline \multirow{2}{*}{7} & Arts (Urban) & \multirow{2}{*}{1.33758} & \multirow{2}{*}{ NS } \\
\hline & Arts (Rural) & & \\
\hline \multirow{2}{*}{8} & Male (Commerce) & \multirow{2}{*}{3.45646} & \multirow{2}{*}{ significant at $p<.01$} \\
\hline & Female (Commerce) & & \\
\hline \multirow{2}{*}{9} & Commerce (Urban) & \multirow{2}{*}{0.48164} & \multirow{2}{*}{ NS } \\
\hline & Commerce (Rural) & & \\
\hline \multirow{2}{*}{10} & Male (Science) & \multirow{2}{*}{1.45612} & \multirow{2}{*}{ NS } \\
\hline & Female (Science) & & \\
\hline \multirow{2}{*}{11} & Science (Urban) & \multirow{2}{*}{2.6289} & \multirow{2}{*}{ significant at $p<.01$} \\
\hline & Science (Rural) & & \\
\hline \multirow{2}{*}{12} & Male (Arts) & \multirow{2}{*}{2.89487} & \multirow{2}{*}{ significant at $p<.01$} \\
\hline & Male (Science) & & \\
\hline \multirow{2}{*}{13} & Male (Arts) & \multirow{2}{*}{2.54338} & \multirow{2}{*}{ significant at $p<.05$} \\
\hline & Male (Commerce) & & \\
\hline \multirow{2}{*}{14} & Female (Arts) & \multirow{2}{*}{6.26964} & \multirow{2}{*}{ significant at $p<.01$} \\
\hline & Female (Science) & & \\
\hline 15 & Female (Arts) & 10017 & cianificht at $n<01$ \\
\hline $1 J$ & Female (Commerce) & 4.7047 & 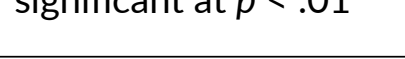 \\
\hline 16 & Male (Arts) & 4.38636 & significant at $n<01$ \\
\hline & Female (Science) & & \\
\hline 17 & Male (Arts) & 4.96047 & significant at $n<01$ \\
\hline & Female (Commerce) & & \\
\hline 18 & Male (Science) & 4.91314 & significant at $n<01$ \\
\hline & Female (Arts) & & \\
\hline 19 & Male (Science) & 8.0438 & significant at $n<01$ \\
\hline & Female (Commerce) & & \\
\hline 20 & Male (Commerce) & 159456 & NS \\
\hline & Female (Arts) & & \\
\hline 21 & Male (Commerce) & 723858 & sjenificant at $\mathrm{n}<01$ \\
\hline 21 & Female (Science) & & \\
\hline
\end{tabular}


Awareness about Muga Culture among the College Students in Jorhat District of Assam, India

\section{CONCLUSION}

From the study, it can be concluded that the awareness level on muga culture among arts, commerce and science stream general college students is not high and significance difference was found among male and female students, rural and urban students, Arts and Science stream students, Arts and Commerce stream students and Science and Commerce stream students. Muga culture is not only a tradition of the people of northeastern region of India but also part of the culture of the region. Based on the findings of the study, youth must be made aware of the benefits of muga culture.

\section{REFERENCES}

Anonymous (2020). Annual Report, 2019-20. Central Silk Board, India, P.95.

Gangwar, R. \& Kameswari, V. L. V. (2016). Determinants of attitude of rural youth towards agriculture as means of livelihood. International Journal of Development Research. 6(09); 9298-9300.

Ghosh, K. \& Saikia, M. (2017). A comparative study on awareness about sericulture among Assamese and English medium secondary school students in Jorhat district of Assam, India. Journal of Entomology and Zoology Studies, 5(4): 520-523.

Goswami, C. \& Bhattacharya, M. (2013). Contribution of Sericulture to Women's Income in Assam -A Case Study in Goalpara District of Assam, India. International Journal of Scientific and Research Publications, 3(3):1-6.

Kushwaha, R.V. \& Singhvi, N.R. (2013). Extent of adoption of improved sericultural practices by the sericulturists of Buldhana district of Maharashtra. Agriculture Update, 8(3):469-471.

Mech, D. \& Ahmed, S. A. (2012). Participatory Profiles of Women in Eri Culture in Assam State of India. European Journal of Applied Sciences, 4(4):177-181.

Rani, A., \& Rampal, V. K. (2016). Involvement of rural youth in agricultural activities in Ludhiana district of Punjab, India. Indian Journal of Agricultural Research. 50 (6):528534.

Saikia, M., Ghosh, K. \& Peigler, R.S. (2016). Factors affecting on quality muga silkworm (Antheraea assamensis Helfer) seed crop production: A review. Journal of Entomology and Zoology Studies. 4(6):806-810.

Sreenivasa, B.T. H. (2014). A study on the factors influencing adoption of new technologies in nontraditional sericultural area of Chitradurga district, Karnataka. Global Journal of Biology, Agriculture \& Health Sciences, 3(1):239-243.

Upadhyay, A.P. \& Barman, U. (2013). Identification of Problems and Formulation of Extension Strategies for Upliftment of Women Agripreneurship in Sericulture: An Exploratory Study in Garo Hills of Meghalaya. Journal of Academia and Industrial Research, 2(6):369-373.

Viswanatha, H., Manjunatha, B.N., Lakshminarayan M.T. \& Anand, T.N. (2014). Participation of Rural Youth in Sericulture. Mysore Journal of Agricultural Sciences, 48(2):251-256. 